\title{
El papel de la ingeniería en el aprovechamiento sostenible de la biodiversidad
}

\author{
The Role of Engineering in Biodiversity Sustainable Use
}

\author{
Luz Marina Mantilla Cárdenas ${ }^{(1)}$ \\ Editora invitada \\ (1) Magister en Gobierno y Políticas Públicas, Universidad Externado de Colombia, Columbia University. Directora General del Instituto \\ Amazónico de Investigaciones Científicas, SINCHI. Bogotá, Colombia. luzmarmantilla@sinchi.org.co
}

Este dossier denominado El papel de la ingeniería en el aprovechamiento sostenible de la biodiversidad presenta tres temas que hoy, en un mundo marcado por la economía verde, cobran importancia en tres escenarios que parecen distantes pero que están articulados por la necesidad de entender las dinámicas naturales a través de su estudio, para aprovechar de manera eficiente y limpia la oferta de la biodiversidad y encontrar puntos de encuentro entre la política y la investigación.

Para las regiones de Colombia es importante que desde el centro del país se entiendan las figuras reconocidas legalmente que influyen en la gobernanza y la gobernabilidad, como los resguardos indígenas, las comunidades afrodescendientes y los raizales, entre otros, ya que, ellos son determinantes en el uso de la biodiversidad como bien común. De esta manera, el artículo $L a$ implementación del Plan Estratégico Nacional de Mercados Verdes en el Departamento de Amazonas, Colombia, 2002- 2011: ¿Acierto o desacierto? muestra cómo la formulación de políticas públicas para el aprovechamiento de la biodiversidad presenta fallas dado que no tiene mecanismos de articulación y desconoce en buena medida los temas asociados a gobernanza y gobernabilidad de las regiones. Aun así, las instituciones del orden nacional hacen esfuerzos importantes en materia de investigación, innovación y transferencia de tecnología, y se logran resultados importantes para la gente, tal como se ve en los emprendimientos del Instituto SINCHI y Corpoamazonia.
Si se entiende que la biodiversidad es de todos, las posibilidades de crecimiento y de alternativas de desarrollo sostenible son enormes para las comunidades, quienes a partir de la generación de capacidades y de la confianza de todos los actores que intervienen en la cadena de valor, pueden ofrecer una amplia gama de productos que van desde los alimentos funcionales para abrir oportunidades en el escenario mundial, hasta la oferta de ingredientes naturales con posibilidades en más de un renglón de los mercados verdes. Es decir, que a nuevas formas de ver la biodiversidad, corresponden nuevas formas de consumo y de producción responsables.

La capacitación sobre modelos de desarrollo apropiados a las regiones puede hacer de ellas territorios competitivos a partir de su oferta de productos derivados de la biodiversidad. Por esto, es importante también que se materialice la integración de las políticas públicas, y que se dé una articulación entre Estado-Universidad-Sector productivo, que contribuya a la estabilidad de los territorios y al aprovechamiento de los recursos de la biodiversidad que hacen que cada región sea única y tenga diversas potencialidades.

El dossier tiene un énfasis particular en la región amazónica colombiana cuyas características biofísicas y sociales son un reto para todas las instancias del país. Los servicios ecosistémicos que ofrece esta región aún requieren estudios, tal como lo plantea Ernesto Guhl en su artículo, que podrían encontrar respuestas en un programa de Ingeniería de los Ecosistemas que "apoye a la naturaleza para lograr la conservación e incluso el aumento de la capacidad de los ecosistemas para generar sus bienes y servicios”. Cabe aclarar que ya hay aplicaciones de la ingeniería dirigidas al aprovechamiento de la biodiversidad, a la mitigación de impactos ambientales, a la transformación de ecosistemas, entre otros aspectos. Esto se puede evidenciar en el artículo El rol de la ingeniería en el aprovechamiento sostenible de la biodiversidad de la Amazonia, en el que diversas ramas de la ingeniería se han encontrado con éxito y han permitido innovación en los desarrollos.

Además de la creación de programas académicos como el propuesto en este dossier y el trabajo interdisciplinario entre ingenierías ya existentes, se encuentra la necesidad de que el Estado logre la integración de sus políticas ambientales de manera que sean ejes transversales en los planes de desarrollo nacional, departamental y local. La continuidad de estas políticas, su articulación con el sector productivo, su adaptación a las regiones y sus singularidades serán, con toda seguridad, una contribución para que el país avance en materia ambiental. También es importante sumar a esta articulación las políticas relativas a ciencia, tecnología e innovación, para garantizar que la información y el conocimiento se generen en el marco de los estándares más altos previstos a nivel mundial.

La biodiversidad es un recurso que debe motivar un cambio de actitud de todos los actores que forman parte de la sociedad y, para este caso particular, de 
la academia, con el fin de lograr la obtención de productos innovadores con criterios de sostenibilidad. Esperamos, entonces, que este dossier sea un punto de partida para la reflexión desde la universidad en el conocimiento, el aprovechamiento y la transformación de la biodiversidad. Esta reflexión debe involucrar modelos de gestión incluyentes que convoquen la participación de las sociedades locales en los escenarios de ciencia y tecnología pertinentes y así, incentivar el uso respetuoso del capital natural de las regiones y promover un desarrollo que resuelva las brechas entre ellas. Igualmente, se debe considerar una articulación apropiada entre los actores involucrados y un convencimiento del poder decisivo de la biodiversidad para que estos actores tengan una nueva visión de futuro. 